Review Article

\section{Psychological phenomena in the doctor- Elderly patient relationship}

\author{
Jose Luis Turabian* \\ Specialist, Family and Community Medicine, Health Center Santa Maria de Benquerencia. Regional \\ Health Service of Castilla la Mancha (SESCAM), Toledo, Spain
}

\section{Abstract}

The doctor-patient communication and the aging of the patients attended by the general practitioner are two important concepts that constantly impact medical consultations. This article raises some reflections and conceptualizations about the main psychological phenomena that have a special importance in the doctor-elderly patient communication and relationship: 1 ) Stereotypes and prejudices; 2) Regression; 3) Transference, countertransference and resistance; 4) Rapport; 5) Empathy; and 6) Paternalism. The GP must be alert about what affecting the communication with the old man and he should put the means to get a warm relationship. Consequently, to achieve effective communication with an older adult: The GP have to take it easy; to be patient; avoiding stereotypes and prejudices; allowing the patient to establish a benign regressive relationship, until if it is possible due to the biopsychosocial context of the elderly patient, he can begin the non-regressive relationship again; recognizing fact of transference, which put the doctor in another place, is inevitable, but taking into account that it greatly affects his relationship with the patients; avoiding countertransference; considering that the therapeutic alliance or rapport is particularly fragile in elderly patients with chronic diseases; giving greater importance to empathy; knowing that the elderly patient frequently accepts the authority of the doctor, but avoiding falling into an iatrogenic paternalism; and smile.

\section{More Information}

*Address for Correspondence: Jose Luis Turabian, Specialist, Family and Community Medicine, Health Center Santa Maria de Benquerencia. Regional Health Service of Castilla la Mancha (SESCAM), Toledo, Spain, Email: jturabianf@hotmail.com

Submitted: 11 March 2020

Approved: 07 April 2020

Published: 08 April 2020

How to cite this article: Turabian JL. Psychological phenomena in the doctor- Elderly patient relationship. Arch Psychiatr Ment Health. 2020; 4: 019-023.

\section{DOI: 10.29328/journal.apmh.1001013}

Copyright: (c) 2020 Turabian JL. This is an open access article distributed under the Creative Commons Attribution License, which permits unrestricted use, distribution, and reproduction in any medium, provided the original work is properly cited.

Keywords: Elderly; Doctor-Patient Communication; Communication Skills; Prejudice; Paternalism; Empathy; Transference (Psychology); General Practice; Framework

Check for updates

OPEN ACCESS

\section{Introduction}

The transcendence of psychological factors of the doctorpatient relationship is given by the fact of its influence on results and quality of medical care, improvement in compliance, satisfaction and recall of physician information, and so they play a fundamental role in the medical care process [1].

To the extent that we respond emotionally to someone, we respond physiologically to that person. Consequently, people in an emotionally significant relationship share physiological responses associated with those emotions. The emotions of fear and pain that accompany patients' symptoms so often are driving them to seek relief through medical care, an important ingredient of which is the doctor's affective care. People in an empathic relationship exhibit a correlation with indicators of autonomic activity. This occurs between speakers and responsive listeners, members of a coherent group, and bonded pairs of higher social animals. Furthermore, the experience of feel cared in a relationship reduces the secretion of stress hormones and shifts the neuroendocrine system toward homeostasis. Because the social engagement of emotions is related simultaneously the social engagement of the physiologic substrate of those emotions, the process has been labelled sociophysiology. This process can influence the health of both parties in the doctor-patient relationship, and may be relevant to third parties [2].

Communication between the patient and doctor is extremely important, especially for the treatment of patients with chronic diseases [3]. In the elderly there is often multimorbidity: osteoarthritis, arterial hypertension, cardiovascular disease, depression, COPD, loss of visual and auditory capacity, falls and immobility, osteoporosis, dementia, delirium, urinary incontinence, etc., and $20 \%$ of them are patients with disabilities. Further, multimorbidity implies polypharmacy, with an average of 4.5 drugs prescribed by the doctor to the older patient. To all this must be added that with aging increases the risk of developing CNS disorders and there may be a cerebral deficit associated with psychological symptoms that reflects psychiatric disturbances. In addition, the elderly may present with Alzheimer's disease, vascular dementia, alcoholic dementia, brain neoplasia, or cranioencephalic trauma, all of which have serious implications for doctor-patient communication $[4,5]$.

The characteristics of the doctor-patient relationship and communication are different in the presence of an elderly 
patient. The communication process can be further complicated by age. Older patients are actually more heterogeneous than younger people. In addition, the normal aging process may involve sensory loss, decreased memory, slower processing of information, decreased power and influence over their own lives, withdrawal from work and separation from family and friends. On the other hand, older patients are more likely to accept medical authority, both in terms of attitudes and behavior, than younger groups.

In consequence, the psychological phenomena between doctors and their elderly patients, thus, are somewhat different in consultations with elderly patients. Poor communication with this vulnerable, and growing, population can undermine GP efforts to provide good patient care [5-8].

In this scenario, this article which is a personal view, aims to reflect, synthesize and conceptualize, based on a selected narrative review and the author's experience, on some psychological phenomena in the doctor-elderly patient relationship in general medicine, and its practical implications.

\section{Discussion}

The main psychological phenomena that have a special importance in communication and elderly patient medical relationship, are stereotypes and prejudices, regression, transference, countertransference and resistance, "rapport," empathy, and paternalism. The understanding of these psychological phenomena is essential for an adequate professional relationship with the elderly (Table 1).

\section{Stereotypes and prejudices}

The term "elderly" does not define age accurately and carries bias and prejudice that lead to harm through discriminatory practices, institutional prejudices, and "ageist" policies in society and medicine. Thus, there may be an unconscious bias of the doctor against the elderly. The bias associated with this term, which is so prevalent in society, can enter medicine and potentially influence first impressions, which in turn affect diagnoses, communication and treatment. In addition, this bias can create damage by promoting unfair social policies. Aging is a gradual process, not a disease. The term elder evokes stereotypes and prejudices that are inappropriate in the medical profession [9].

Old age has often been viewed from a negative perspective, as a period characterized exclusively by loss, deprivation and demotivation, and by the continuous and irreversible

\begin{tabular}{|c|c|}
\hline 1 & -Stereotypes and prejudices \\
\hline 2 & -Regression \\
\hline 3 & -Transference, countertransference and resistance \\
\hline 4 & -Rapport \\
\hline 5 & -Empathy \\
\hline 6 & -Paternalism \\
\hline
\end{tabular}

deterioration of abilities, especially in mental abilities. As frail older people might have difficulties in expressing themselves, their needs are often interpreted by others, for example, by significant others, whose information GP often have to rely on. This, in turn, can put the GP in ethically difficult situations, where they have to choose between alternative courses of action. It is of importance that GPs listen to both the frail older person and their significant other (s) and be aware of whose voice that the care given is based on, in order to provide care that is beneficial and not to the detriment of the older person [10].

\section{Regression}

It is one of the defense mechanisms against the disease (others would be surprise and denial, frustration and anger, repression or rejection, negotiation, depression, resignation and acceptance). It is a psychoanalytic phenomenon that consists in returning to an earlier stage of evolutionary development. The accepted regression it must be in a fair degree, thinking that the patient will recover the greatest possible degree of autonomy. This process would occur in response to unacceptable thoughts or impulses that the person cannot cope with adaptively, and could be transient or chronic. A very remarkable feature of this phenomenon is the appearance of typically childish behaviors and attitudes. It is activated by anguish or insecurity and the stage at which the subject "returns" is the one that gave him greater emotional security. For example: Patients who demand more attention or even need to help them eat, or not to be alone during the night.

Regression includes immature and adaptive behaviors, such as capricious behavior, demands for continuous attention, poor collaboration, etc. The intensity of the regression usually depends on the degree of anxiety of the patient, and disappears when health and self-confidence are restored. But, the old people lives his illness feeling very exposed to complications and eventualities due to his fragility, with maladjustment and anguish. For the elderly, the pain is closely linked to the sense of illness and their suffering is experienced as the direct consequence of this. The old patient expresses less the fear of death as suffering. The disease can emotionally destabilize to the elderly. For the elderly to be ill accentuates their perception of being a burden for others and this increase the awareness of not being able to adapt to their tasks. While in young ages the disease is considered a temporary event, in the elderly it is seen as a structural situation, an intrinsic element of the person $[4,5]$.

This regression phenomenon had already been discovered by Freud, but could not deepen the investigation of this phenomenon with his patients. At the base of the Ferenczi and Balint technical tests is the debated concept of childhood trauma. His theory postulates that, at first, every child is exposed to trauma due to excessive or defective stimulation of the environment, that is, of the adults around him. In a second moment, when the child tries to seek comfort, adults 
- who do not have the least awareness of what happened and, therefore, do not feel guilty - do not respond adequately to the child's demand. Hence the need that child feels, when he reaches adulthood, to return to the moment prior to the traumatic situation, before moving forward, to start over (what Balint will call new beginning) and allow for more adequate relationships.

The disease in the elderly patient tends to create important psychological connotations different from those of other stages of life. One of the elder's biggest concerns is the loss of self-sufficiency. The disease can cause the fear of chronicity, of disability, which intensifies the emotional intensity, and the connotation of abandonment, marginalization and poverty [7].

It may happen that, in consultation with the elderly patient, the GP is an object that he feels unsafe, and that is why he is eagerly demanded of acts that, instead of calming the patient's needs, intensify them more and more, making him a true "addict" to the GP. To this malignant regression Balint also calls it as regression aimed at gratification. Thus, every regression is a demand to return to a particular form of relationship. The GP in the communication and relationship with the elderly patient should allow him to establish a benign regressive relationship, until if it is possible due to the biopsychosocial context of the elderly patient, the non-regressive relationship can begin again [11-13].

\section{Transference, countertransference and resistance}

Transference refers to the emotions of the elderly patient towards the doctor (positive or negative feelings); Countertransference are the emotional reactions of the doctor towards the elderly patient, such as feelings (frustration) and behaviors (rudeness, shortening of the encounter); It is the transference made by the professional in response to the patient's first transference. This is the phenomenon in which the patient puts the doctor in the role of another, and the professional enters his game by putting the patient in the place of another person important to the doctor. Although they are very frequent reactions in normal life, they are not advisable in the doctor-patient relationship. The fact of patient' transference putting the doctor in another place is inevitable, but it is not advisable for the GP to do the same: he must avoid, or at least knowing, transference and countertransference. The importance is that when the doctor does not recognize this kind of response, they greatly affect his relationship with patients. The more helpless the patient feels, the more he will tend to create fantasies in a magical plan in doctor-patient relationship, attributing to doctor a powerful ability, going on to demand from the doctor a miracle, and collaborating little in his healing [14].

Psychodynamically, the GP and the patient interact consciously and unconsciously, they are two different personalities. It must be remembered that the sick see the GP as a figure of structured authority according to their needs and fantasies, they look for a model that provides them with tranquility, confidence and recognition, that someone will restore their health, with hopes of healing and life. These are unconscious and neurotic experiences that the patient has in front of his doctor in relation to childhood experiences and with affective and/or authority figures. The feelings, attitudes and desires, originally linked to important figures of the first years of life, are projected on other people in this case in the doctor who represents those at the present time. So, as this phenomenon in the consultation tis a symbolic representation of these childhood experiences, the doctor is perceived as a father or a mother, from it derive from the reactions of submission or challenge to the authority.

Within the findings in the transference, doctors are seen as authority figures, but ambiguous because they intersect with a paternalistic position of overprotection. The professional is perceived as an almost perfect figure with few human characteristics; unconsciously he stands as a person who does not suffer, sick or has no defects; an idealized character is created. In this case they are good patients, who admire the doctor, blindly obey the indications and adhere to the treatment, the relationships are long and fruitful, creating a therapeutic friendship [7].

However, some patients have resistance reactions, which go against the relationship with the doctor, and they may constitute negative forces that favor non-adherence to treatment and medical indications. Patients who have problems with authority react to the contrary, rebel, challenge and question it, do not react with submission, do not adhere to treatment as a manifestation of nonconformity and rebellion. They are sick who wander from doctor to doctor, are characterized by disbelief and distrust, take aggressive attitudes in a covert or open manner, and are considered bad patients. In these cases, in the course of the clinical interview, the GP can react negatively, since he translates it as an aggression against narcissism and the power of his authority.

Countertransference is an act that arises in the doctorbecause of the influence that the patient exerts on his unconscious feeling. For some authors, countertransference includes the capacity for empathy, antipathy, sympathy and other affections, the mental functioning of the doctor, his failures, conflicts and problems [15].

\section{Rapport}

Rapport is a word of French origin ("rapporter"), which means "bring back" or "create a relationship". It is the degree of affective contact between patient and therapist. The rapport includes the state of mutual trust and respect between the doctor and the elderly patient. Rapport is related to the "therapeutic alliance" construct; This concept of therapeutic alliance has its origin within the psychoanalytic model. Freud, although he did not use this concept as such, announced that before the 
therapist gives the patient his first interpretations, an adequate rapport must be established in the relationship [16].

The therapeutic alliance or rapport is particularly fragile in chronic diseases and in polymedicated and multipathological elderly patients. Rapport construction includes smiling, calling the patient by name, being optimistic, having patience, and looking for connections (understanding the patient's universe, trying to find any information that connects us).

\section{Empathy}

Empathy is a complex human experience that involves the subjective intersection of different individuals. In the context of general medicine care in the geriatric setting, the benefits of empathetic relationships are directly related to the quality of the practice [17].

In communicating with elderly patients it is necessary to give greater importance to empathy [5]. Empathy is the doctor's ability to receive and decode the affective communication of his elderly patient; this can allow the understanding of the patient's feelings. Even when older patients have appropriate access to medical services, they also need effective and empathic communication as an essential part of their treatment [18]. So, the GP should pay attention to the opportunities to respond to the emotions of patients, using appropriate phrases [19].

Studies show that clinical empathy can be learned and practiced and that it adds less than a minute to the patient interview. It also has rewards in terms of patient satisfaction, understanding and adherence to treatment [20]. The lack of empathy of the GP to the elderly patient unconsciously represents fear of old age and the fact of not perceiving the limitations of the elderly own world [15].

\section{Paternalism}

Elderly patients are more likely to accept the doctor's authority, both in terms of attitudes and behavior, than younger groups [5], and this carries the risk of the GP acting with paternalism. Historically, doctors have been responsible for decisions related to the care of their patients assuming an eminently paternalistic stance [21]. Paternalism in medicine occurs when we try to make health care decisions for others without their desire or consent [9]. The doctor acts as the guardian of the patient, as a good father who knows what is best for the patient, without his participation being necessary. It usually involves an attitude of omnipotence in the doctor, who give advice on private matters, creating iatrogenesis. Paternalism and omnipotence often conceals feelings of helplessness, and can be the path to a "therapeutic fierceness" that responds to the denial of that impotence by the GP [22].

\section{Conclusion}

The psychological theory of aging is characterized by behavioral changes that are related to environmental influences that influence and are reflected positively or negatively in older adults. Every older person is an individual to whom every vital experience and every modification in their environment has an effect on them. Since the doctor-patient communication and the aging of the patients attended by the general practitioner are two important concepts that constantly impact medical consultations, here are some reflections and conceptualizations about the main psychological phenomena that have a special importance in doctor-elderly patient relationship. The GP should be alert about what is affecting the communication in the old patient, to who he is treating, and so provide the means to get a warm relationship. To achieve effective communication with an older adult, at least the following concepts can be pointed out: you have to take it easy; be patient; avoiding stereotypes and prejudices; allowing the patient to establish a benign regressive relationship, until if it is possible due to the biopsychosocial context of the elderly patient, he can begin the non-regressive relationship again; recognizing that the fact of transference from patient, which put the doctor in another place is inevitable, but taking into account that it greatly affects his relationship with the patients; avoiding countertransference; considering that the therapeutic alliance or rapport is particularly fragile in elderly patients with chronic diseases; giving greater importance to empathy; knowing that the elderly patient frequently accepts the authority of the doctor, but avoiding falling into an iatrogenic paternalism; and smile.

\section{References}

1. Turabian JL. Psychology of doctor-patient relationship in general medicine. Arch Community Med Public Health. 2019; 5: 62-68.

2. Adler HM. The Sociophysiology of Caring in the Doctor-patient Relationship. J Gen Intern Med. 2002; 17: 883-890.

PubMed: https://www.ncbi.nlm.nih.gov/pubmed/12406360

3. Farin E. Patient-provider communication in chronic illness: current state of research in selected areas. Rehabilitation (Stuttg). 2010; 49: 277-291.

PubMed: https://www.ncbi.nlm.nih.gov/pubmed/20963669

4. Cesa-Bianchi M, Critini C, Cesa-Bianchi G.. Anziani e comunicazione tra salute e malatia. Milano: Guidotti. 2000.

5. Turabian JL. Differential Characteristics in Communication and Relationship of the General Practitioner with the Elderly Patient. J Fam Med. Forecast. 2019; 2: 10-17.

6. Robinson II TE, White GL, Houchins JC. Improving Communication With Older Patients: Tips From the Literature. Fam Pract Manag. 2006; 13: 73-78.

PubMed: https://www.ncbi.nlm.nih.gov/pubmed/17022433

7. Turabian JL. Relevant Characteristics for Elderly Patient Biopsicosocial Care in General Medicine. Archives of Community and Family Medicine. 2019; 2: 48-55

8. Reyes Ortiz CA, Gheorghiu S, Mulligan T. Oblivion of psychological phenomena in the elderly doctor-patient relationship. Colombia Médica. 1998; 29.

9. Hekmat-panah J. The "Elderly" in Medicine: Ethical Issues Surrounding This Outdated and Discriminatory Term. Inquiry. 2019. 
10. Larsson $H$, Edberg A-K, Bolmsjö I, Rämgård $M$. Contrasts in older persons' experiences and significant others' perceptions of existential loneliness. Nurs Ethics. 2019; 26: 1623-1637.

PubMed: https://www.ncbi.nlm.nih.gov/pubmed/29772961

11. Daurella N. Basic failure and therapeutic relationship: the contribution of Michael Balint to the relational conception of psychoanalysis. Temas de Psicoanálisis. Revista de la Sociedad Española de Psicoanálisis. 2019; 18.

12. Balint M. Thrills and regressions. Londres: Hogarth Press. 1959.

13. Balint M. The Basic Fault: Therapeutic Aspects of Regression. Londres: Tavistock Publications. 1968.

14. Kvale JN, Dayringer R. The transference phenomenon in the care of the elderly patient. Fam Med. 1987; 19: 141-143.

PubMed: https://www.ncbi.nlm.nih.gov/pubmed/3596096

15. Urbina-Méndez R, Hernández-Vargas $\mathrm{Cl}$, Hernández-Torres I, Fernández-Ortega MA, Irigoyen-Coria A. Psychodynamic Analysis of Transference and Countertransference in the Formation of Family Physicians in Mexico. Atención Familiar. 2015; 22: 33-62.

16. Strachey J. The Standard Edition of the Complete Psychological Works of Sigmund Freud, Volume XII (1911-1913): The Case of Schreber
Papers on Technique and Other Works. ii-vii. The Hogarth Press and the Institute of Psycho-analysis, London. 1958.

17. Teófilo TJS, Veras RFS, Silva VA, Cunha NM, Oliveira J dos S, et al. Empathy in the nurse-patient relationship in geriatric care: An integrative review. Nurs Ethics. 2019; 26: 1585-1600.

PubMed: https://www.ncbi.nlm.nih.gov/pubmed/30071772

18. Williams SL, Haskard KB, DiMatteo MR. The therapeutic effects of the physician-older patient relationship: Effective communication with vulnerable older patients. Clin Interv Aging. 2007; 2: 453-467. PubMed: https://www.ncbi.nlm.nih.gov/pubmed/18044195

19. Coulehan JL, Platt FW, Egener B, Frankel R, Lin CT, et al. "Let Me See If I Have This Right...": Words That Help Build Empathy. Ann Intern Med. 2001; 135: 221-227.

PubMed: https://www.ncbi.nlm.nih.gov/pubmed/11487497

20. Talking with Your Older Patient. Understanding Older Patients. NIH. National Institute on Aging

21. Cañete Villafranca R, Guilhem D, Brito Pérez K. Medical paternalism. Rev Med Electrón. 2013; 35.

22. McKinstry B. Paternalism and the doctor-patient relationship in general practice. Br J Gen Pract. 1992; 42: 340-342.

PubMed: https://www.ncbi.nlm.nih.gov/pubmed/1457157 